and French Canada, who challenged the imperial agenda of the organization. This work thus encourages us to think more closely about the way that the discourses and agendas of the organization were responded to and lived-out by members themselves.

Guiding Modern Girls does raise some interesting and important additional questions. Alexander's study is largely focused on discourses around, education for, and responses of girls. However, the role of adult women in both reinforcing and challenging the conservative agenda of the organization is considered more briefly. Further reflection on the lifecycle in relation to Guiding could allow us to understand the longer-term impact of Guiding on members beyond adolescence and could provide an illuminating case study of the ways that Guiding discourse reflected, shaped and even challenged wider public discourse around the role of women in these different societies. Beyond this, more could have been said about the way paid work was positioned and understood by the movement, which perhaps might have further illuminated the role of class as a shaping factor in discourses surrounding femininity within the organization.

Nonetheless, Alexander paints a complex image of the organization, which was the epitome of the simultaneously dynamic and traditional nature of British society in the interwar period, and makes a significant contribution to our understanding of the Girl Guides through this thought-provoking transnational study. In doing so, this work challenges historians of the organization to go beyond national boundaries and think inventively about the source bases available to us. This book also invites a readership from historians interested in the wider history of gender and colonialism, as it illuminates the tensions at play within modern discourses of citizenship and highlights the ways that girls' navigated and responded to contradictory messages regarding their role in the British Empire.

Sian Edwards

University of Winchester

Derrick Darby and John L. Rury

The Color of Mind: Why the Origins of the Achievement Gap Matter for Justice

Chicago: University of Chicago Press, 2018. 202 pp.

The achievement gap between white and black students in the United States continues to be a major area of concern for school leaders and educational policy makers. In The Color of Mind: Why the Origins of the Achievement Gap Matter for Justice, Derrick Darby and John L. Rury trace the origins and history of research documenting the alleged mental and physical differences between white and black students to argue that "the Color of Mind has served to rationalize racially exclusionary school practices and unequal educational opportunities, and the effects of these, in turn have worked to sustain this racial ideology" (2). The authors define the "Color of Mind" broadly as the historical idea that "blacks were not equals to whites in intelligence, character, 
and conduct" (2). The book is the latest entry in the History and Philosophy of Education Series by the University of Chicago Press, which offers co-written analyses of current issues by philosophers and historians. Darby is a philosopher at the University of Michigan, and Rury is an educational historian at the University of Kansas. While I applaud the idea of combining humanity-based approaches to educational problems, this study offers only a partially successful contribution to the history of the achievement gap issue.

The book enters a crowded field of excellent studies on theories of racial difference and their impact on policy. Stephen Jay Gould's best-selling Mismeasure of Man covers similar ground as the Color of Mind, but does so with greater nuance and attention to chronology. Daryl Michael Scott's Contempt and Pity traces theories of the allegedly damaged black psyche and its impact on social policy. Richard Valencia's edited volume The Evolution of Deficit Thinking looks specifically at psychology's role in establishing dismissive approaches to African American intellectual potential and, like The Color OfMind, links these past racist theories to the cultural deficit models of the present. More recently, Ibram X. Kendi's award-winning Stamped from the Beginning offers a comprehensive account of racist ideas in America, including an account of the achievement gap. Unlike Darby and Rury, Kendi dismisses the achievement gap idea itself, calling it a racist idea, or worse, "a widely used racist slur." These previous studies offer more thorough and nuanced accounts of the impact of racist ideas on educational policy than The Color of Mind. The authors would have benefitted from consulting these sources. However, they only seem to have been aware of Gould's well-known book.

The Color of Mind opens with a philosophical case for "dignitary justice" towards students of color by demonstrating how black-white disparities in test scores, underenrollment of black students in high-status classes, and over-representation of black students for punitive school discipline and special education services suggests that "these kids are not persons with equal dignity" (28). These disparities, the authors argue, both reflect and perpetuate the Color of Mind idea. The dignitary justice rationale was new to me. I found it more convincing than previous rationales for closing the achievement gap, such as merely expanding educational opportunity for underserved groups or unleashing the untapped economic potential of the oppressed. However, given the novelty of the dignitary justice idea, I wished that the authors had provided a more robust philosophical justification than the mere page and a half they offer in the introduction.

Chapters 2 through 4 trace the origins of the Color of Mind idea to Enlightenment thinkers such as David Hume, Thomas Jefferson, and Immanuel Kant, and later Ralph Waldo Emerson. These are the weakest chapters of the book. By conflating centuries of racial theories into the Color of Mind concept, the authors pull quotations out of historical context, offer superficial analysis of specific racial theories, and overlook entire conceptual racial frameworks, such as the ethnocentric theory of recapitulation, which related the cultural/psychological development of the human race to the linear development of the white child. These chapters also contain some factual errors. For example, the Army Alpha test was not "the earliest comprehensive 
assessment of racial achievement gap in history" (61). A 1913 study by Marion J. Mayo, The Mental Capacity of the American Negro predated the Army study by three years and actually used student grades in New York, St. Louis, Memphis, and Nashville to suggest that black-white disparities may be due more to environment than hereditary endowment. A more egregious error was the authors' use of a speech by Kelly Miller "of Hampton Institute" to represent the racial thinking of "white intellectuals" at the time (57). Miller never taught at Hampton and was actually a professor at Howard University. More significantly, Miller was black, not white. By getting Miller's race wrong, the authors not only made an unfortunate factual error, but they squandered an opportunity to discuss how some black intellectuals absorbed and employed some of the racist theories put forth by whites in a desperate attempt to reach a broader audience for their ideas. By chapter 4, things improve significantly, as the authors discuss the shift from innate to cultural explanations of racial deficits in the 1960s, and trace how legal structures, social policies, and curriculum tracking have exacerbated segregated schools in recent years. They conclude with additional evidence for racial disparities in education and suggest that administrators de-track their schools and compile a "Color of Mind index" to record and reduce racial disproportionalities. The authors see the achievement gap as mainly an administrative issue, so there is no discussion of pedagogy, curriculum, or instruction.

Darby and Rury were not likely aiming to make a major historiographical contribution with this book. The intended audience seems to be school administrators and policy makers. With this in mind, the book succeeds in putting information about racial disparities in education in one place by providing a readable and concise account of the history of the social construction of the achievement gap. However, as mentioned above, other scholars have addressed this topic with greater precision and depth, and readers looking for ideas for how teachers can tackle the achievement gap from an instructional or pedagogical perspective will need to look elsewhere, such as Tyrone Howard's Why Race and Culture Matter in Schools: Closing the Achievement Gap in America's Classrooms.

Thomas Fallace

William Paterson University

\section{Cecilia Morgan \\ Travellers through Empire: Indigenous Voyages from Early Canada}

Montreal \& Kingston: McGill-Queens University Press, 2017. 326 pp.

In this superb study of Indigenous mobility throughout the nineteenth-century Atlantic world, Cecilia Morgan argues that Native travellers resisted colonialism in Upper Canada by "deliberately" crossing "numerous boundaries and borders" (3). Indigenous mobility, however, is not the newest of historiographical stories. For decades historians have written about the centrality of mobility to Shawnee survival, 